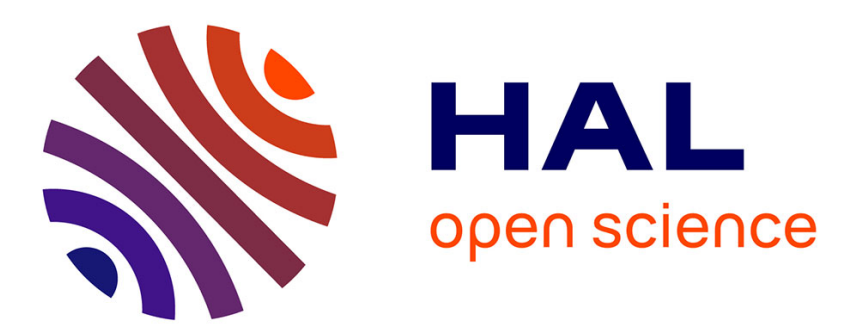

\title{
Temperature-dependent rate constant for the reaction of F atoms with HNO 3
}

Yuri Bedjanian

\section{To cite this version:}

Yuri Bedjanian. Temperature-dependent rate constant for the reaction of $\mathrm{F}$ atoms with HNO 3. International Journal of Chemical Kinetics, 2019, 51 (10), pp.753-759. 10.1002/kin.21306 . hal02268337

\section{HAL Id: hal-02268337 \\ https://hal.science/hal-02268337}

Submitted on 12 Jan 2022

HAL is a multi-disciplinary open access archive for the deposit and dissemination of scientific research documents, whether they are published or not. The documents may come from teaching and research institutions in France or abroad, or from public or private research centers.
L'archive ouverte pluridisciplinaire HAL, est destinée au dépôt et à la diffusion de documents scientifiques de niveau recherche, publiés ou non, émanant des établissements d'enseignement et de recherche français ou étrangers, des laboratoires publics ou privés. 


\title{
Temperature Dependent Rate Constant for the Reaction of F- Atoms with $\mathrm{HNO}_{3}$
}

\author{
YURI BEDJANIAN*
}

Institut de Combustion, Aérothermique, Réactivité et Environnement (ICARE), CNRS, 45071 Orléans Cedex 2, France

ABSTRACT: The kinetics of the reaction of F-atom with $\mathrm{HNO}_{3}$, source of $\mathrm{NO}_{3}$ radicals widely used in laboratory studies, has been investigated at nearly 2.7 mbar total pressure of helium over a wide temperature range, $\mathrm{T}=220-700 \mathrm{~K}$, using a low pressure discharge flow reactor combined with an electron impact ionization quadrupole mass spectrometer. The rate constant of the reaction $\mathrm{F}+\mathrm{HNO}_{3} \rightarrow \mathrm{NO}_{3}+\mathrm{HF}$ (1) was determined using both relative rate method and absolute measurements under pseudo-first order conditions, monitoring the kinetics of F-atom consumption in excess of $\mathrm{HNO}_{3}, k_{1}=(6.1 \pm 0.4) \times 10^{-12} \exp ((155 \pm 18) / \mathrm{T})$ $\mathrm{cm}^{3}$ molecule $\mathrm{s}^{-1}$ (where the uncertainties represent precision at the $2 \sigma$ level, the estimated total uncertainty on $k_{1}$ being $15 \%$ at all temperatures). The reaction rate constant was found to be in excellent agreement with the only previous temperature dependent study. Experiments on detection of the reaction product, $\mathrm{HF}$, have shown that $\mathrm{NO}_{3}$ and $\mathrm{HF}$ forming channel of the title reaction is the dominant, if not unique, on the whole temperature range of the study.

Keywords: Fluorine atom, nitric acid, $\mathrm{NO}_{3}$ radical, rate coefficient, temperature dependence.

*Correspondence to: Yuri Bedjanian: Tel.: +33 238255474, e-mail: yuri.bedjanian@cnrs-orleans.fr 


\section{INTRODUCTION}

Nitrate radical $\left(\mathrm{NO}_{3}\right)$, which is formed in the atmosphere mainly in the reaction of $\mathrm{NO}_{2}$ with ozone, is an important atmospheric oxidant, particularly in nighttime chemistry [1]. Understanding of the atmospheric photochemistry of $\mathrm{NO}_{3}$ requires experimental kinetic and spectroscopic studies of the processes in which it is involved. Reaction

$$
\mathrm{F}+\mathrm{HNO}_{3} \rightarrow \mathrm{NO}_{3}+\mathrm{HF}
$$

is a convenient source of nitrate radicals and is very often used for generation of $\mathrm{NO}_{3}$ in laboratory studies. However, despite its frequent use and importance, the temperature dependence of the rate constant of reaction (1) was investigated in only one (for temperatures between 260 and $373 \mathrm{~K}$ [2]) from four available in the literature kinetic studies [2-5]. In this paper, we report the measurements of the rate constant of the reaction of fluorine atoms with nitric acid as a function of temperature in an extended temperature range, 220-700 K.

\section{EXPERIMENTAL}

Experiments were carried out in a discharge flow reactor using a modulated molecular beam electron ionization mass spectrometer as the detection method [6,7]. Two flow reactors were used. The first one, used at low temperatures $(220-320 \mathrm{~K})$, consisted of a Pyrex tube $(45 \mathrm{~cm}$ length and $2.4 \mathrm{~cm}$ i.d.) with a jacket for the thermostated liquid circulation (ethanol). The walls of the reactor as well as of the movable injector of fluorine atoms were coated with halocarbon wax (HW) in order to minimize their heterogeneous loss. The second flow reactor used at high temperatures $(\mathrm{T}=310-700 \mathrm{~K})$, consisted of an electrically heated Quartz tube (45 cm length and $2.5 \mathrm{~cm}$ i.d.) with water-cooled attachments (Fig. 1) [8].

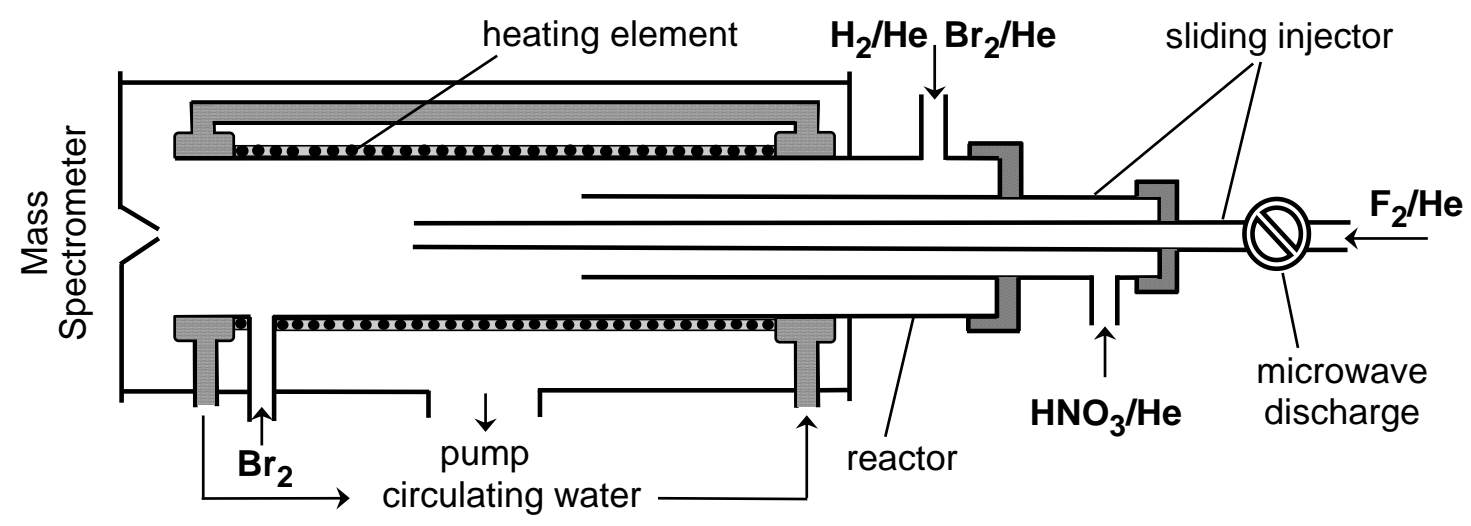

Figure 1 Diagram of the flow reactor. 
Fluorine atoms were generated from the microwave discharge in $\mathrm{F}_{2} / \mathrm{He}$ mixtures (Fig. 1). To reduce $\mathrm{F}$ atom reactions with glass surface inside the microwave cavity, a ceramic $\left(\mathrm{Al}_{2} \mathrm{O}_{3}\right)$ tube was inserted into this part of the injector. Mass spectrometric monitoring of molecular fluorine showed that more than $90 \%$ of $\mathrm{F}_{2}$ was dissociated in the microwave discharge. Fatoms were detected at $\mathrm{m} / \mathrm{z}=98 / 100\left(\mathrm{FBr}^{+}\right)$after being scavenged with an excess of $\mathrm{Br}_{2}$ (added in the end of the reactor $6 \mathrm{~cm}$ upstream of the sampling cone as shown in Fig. 1) through reaction (2):

$$
\begin{aligned}
& \mathrm{F}+\mathrm{Br}_{2} \rightarrow \mathrm{Br}+\mathrm{FBr} \\
& k_{2}=(1.28 \pm 0.20) \times 10^{-10} \mathrm{~cm}^{3} \text { molecule }^{-1} \mathrm{~s}^{-1}(\mathrm{~T}=299-940 \mathrm{~K})[9] .
\end{aligned}
$$

This reaction was also used for the determination of the absolute concentrations of F-atoms through their chemical conversion to $\mathrm{FBr}$ in excess of $\mathrm{Br}_{2}:[\mathrm{F}]=[\mathrm{FBr}]=\Delta\left[\mathrm{Br}_{2}\right]$, i.e. concentration of $\mathrm{F}$-atoms $(\mathrm{FBr})$ was determined from the consumed fraction of $\left[\mathrm{Br}_{2}\right]$.

The $\mathrm{HNO}_{3}$ vapors were delivered to the reactor by flowing the bath gas $(\mathrm{He})$ over thermostated (at nearly $0{ }^{\circ} \mathrm{C}$ ) $\mathrm{HNO}_{3}\left(70 \%\right.$ in water) $/ \mathrm{H}_{2} \mathrm{SO}_{4}$ mixture (in an approximate $1: 3$ ratio) or from flask with a known $\mathrm{HNO}_{3} / \mathrm{He}$ mixture and were detected by mass spectrometry at $\mathrm{m} / \mathrm{z}=63$ and $46\left(\mathrm{HNO}_{3}{ }^{+}\right.$and $\left.\mathrm{NO}_{2}{ }^{+}\right)$. The $\mathrm{H}_{2} \mathrm{O}$ impurity in the gaseous samples of $\mathrm{HNO}_{3}$, directly detected at $\mathrm{m} / \mathrm{z}=18\left(\mathrm{H}_{2} \mathrm{O}^{+}\right)$, was always less than $1 \%$. Absolute concentrations of $\mathrm{HNO}_{3}$ as well of the other stable species $\left(\mathrm{NO}, \mathrm{NO}_{2}, \mathrm{~F}_{2}, \mathrm{H}_{2}\right.$ and $\left.\mathrm{Br}_{2}\right)$ were calculated from their flow rates obtained from the measurements of the pressure drop of their mixtures in He stored in calibrated volume flasks. For absolute calibration of $\mathrm{HNO}_{3}$ another method, linking $\mathrm{HNO}_{3}$ and $\mathrm{Br}_{2}$ concentrations, was also employed. It consisted in titration of the same concentration of $\mathrm{F}$ atoms with excess $\mathrm{Br}_{2}\left([\mathrm{~F}]_{0}=\Delta\left[\mathrm{Br}_{2}\right]\right)$ and $\mathrm{HNO}_{3}\left([\mathrm{~F}]_{0}=\Delta\left[\mathrm{HNO}_{3}\right]\right)$. This procedure allowed absolute calibration of $\mathrm{HNO}_{3}$ signals using that of $\mathrm{Br}_{2}$. The absolute concentrations of $\mathrm{HNO}_{3}$ determined with two employed methods were consistent within $10 \%$. All species were detected by mass spectrometry at their parent peaks: $m / z=63\left(\mathrm{HNO}_{3}{ }^{+}\right), 46\left(\mathrm{NO}_{2}{ }^{+}\right), 30\left(\mathrm{NO}^{+}\right)$, $160\left(\mathrm{Br}_{2}^{+}\right), 98 / 100\left(\mathrm{BrF}^{+}\right), 38\left(\mathrm{~F}_{2}^{+}\right), 20\left(\mathrm{HF}^{+}\right), 18\left(\mathrm{H}_{2} \mathrm{O}^{+}\right)$. The contribution of $\mathrm{NO}_{2}$ at $\mathrm{m} / \mathrm{z}=30$ $\left(\mathrm{NO}^{+}\right)$due to fragmentation of $\mathrm{NO}_{2}$ in the ion source of the mass spectrometer (operated at 25-30 eV energy) could be easily determined by simultaneous detection of the signals from $\mathrm{NO}_{2}$ at $m / z=46$ and 30 .

\section{RESULTS AND DISCUSSION}

\section{Rate Constant of reaction (1)}


Absolute measurements. The rate constant of the title reaction was determined under pseudofirst order conditions monitoring F-atom decays in excess of $\mathrm{HNO}_{3},[\mathrm{~F}]=[\mathrm{F}]_{0} \times \exp \left(-k_{1}{ }^{\prime} \times \mathrm{t}\right)$, where $[\mathrm{F}]$ and $[\mathrm{F}]_{0}$ are the time-dependent and initial concentrations of $\mathrm{F}$ atoms, respectively, and $k_{1}{ }^{\prime}=k_{1} \times\left[\mathrm{HNO}_{3}\right]+k_{\mathrm{w}}$ is the pseudo-first-order rate constant with $k_{\mathrm{w}}$ representing the loss of $\mathrm{F}$ atoms in the absence of nitric acid in the reactor. Initial concentration of fluorine atoms in these experiments was in the range $(2-5) \times 10^{11}$ molecule $\mathrm{cm}^{-3}$; the concentrations of $\mathrm{HNO}_{3}$ are shown in Table I. The flow velocity in the reactor was in the range (2210-3030) $\mathrm{cm} \mathrm{s}^{-1}$. The pseudo-first-order rate constants were determined from the exponential fit to F-atom consumption kinetics: an example is shown in Fig. 2.

Table I Reaction $\mathrm{F}+\mathrm{HNO}_{3}$ : Summary of the Measurements of the Rate Constant

\begin{tabular}{|c|c|c|c|c|c|}
\hline$T(\mathrm{~K})$ & $\begin{array}{l}\text { number of } \\
\text { kinetic runs }\end{array}$ & $\begin{array}{c}{\left[\mathrm{HNO}_{3}\right]} \\
\left(10^{13} \text { molecule } \mathrm{cm}^{-3}\right) \\
\end{array}$ & $\begin{array}{c}k_{1}^{a} \\
\left(10^{-11} \mathrm{~cm}^{3} \mathrm{molecule}^{-1} \mathrm{~s}^{-1}\right)\end{array}$ & $\begin{array}{l}\text { reactor } \\
\text { surface }^{b}\end{array}$ & method $^{c}$ \\
\hline 220 & 8 & $0.10-1.47$ & 3.30 & HW & AM \\
\hline 233 & 7 & $0.13-0.99$ & 3.11 & HW & $\mathrm{AM}$ \\
\hline 235 & 8 & $0.10-1.49$ & 3.17 & HW & $\mathrm{AM}$ \\
\hline 237 & 8 & $0.06-0.67$ & 3.05 & HW & $\mathrm{AM}$ \\
\hline 253 & 8 & $0.10-1.50$ & 2.87 & HW & $\mathrm{AM}$ \\
\hline 273 & 8 & $0.10-1.50$ & 2.71 & HW & $\mathrm{AM}$ \\
\hline 298 & 10 & $0.15-1.91$ & 2.33 & HW & AM \\
\hline 310 & 8 & $0.07-1.41$ & 2.31 & $\mathrm{Q}$ & $\mathrm{AM}$ \\
\hline 320 & 8 & $0.18-1.63$ & 2.25 & HW & $\mathrm{AM}$ \\
\hline 339 & 10 & $1.17-66.7$ & 2.12 & BA & $\mathrm{RM}$ \\
\hline 340 & 9 & $0.12-3.70$ & 2.07 & BA & $\mathrm{AM}$ \\
\hline 390 & 10 & $1.65-61.8$ & 1.92 & BA & $\mathrm{RM}$ \\
\hline 420 & 14 & $0.32-4.20$ & 1.75 & BA & $\mathrm{AM}$ \\
\hline 460 & 24 & $1.02-76.5$ & 1.64 & BA & $\mathrm{RM}$ \\
\hline 460 & 16 & $0.09-2.47$ & 1.58 & $\mathrm{Q}$ & $\mathrm{AM}$ \\
\hline 500 & 9 & $0.12-5.12$ & 1.51 & BA & $\mathrm{AM}$ \\
\hline 550 & 8 & $1.20-59.2$ & 1.40 & BA & $\mathrm{RM}$ \\
\hline 615 & 8 & $0.24-6.6$ & 1.33 & BA & $\mathrm{AM}$ \\
\hline 700 & 10 & $1.12-37.7$ & 1.33 & BA & $\mathrm{RM}$ \\
\hline
\end{tabular}

${ }^{a}$ Estimated uncertainty on $k_{1}$ is 15 and $20 \%$ for absolute and relative rate measurements, respectively.

${ }^{b}$ HW: halocarbon wax; Q: quartz; BA: boric acid.

${ }^{c}$ AM: absolute measurements; RM: relative rate measurements.

The consumption of the excess reactant, $\mathrm{HNO}_{3}$, was observed to be insignificant (within a few percent), although reaching up to $20 \%$ in a few kinetic runs: in all cases the average 
concentration of excess reactant along the reaction zone was used in the calculation of the reaction rate constant. Examples of the dependencies of the pseudo-first order rate constant, $k_{1}{ }^{\prime}$, on concentration of excess reactant, $\mathrm{HNO}_{3}$, at different temperatures are shown in Fig. 3 .

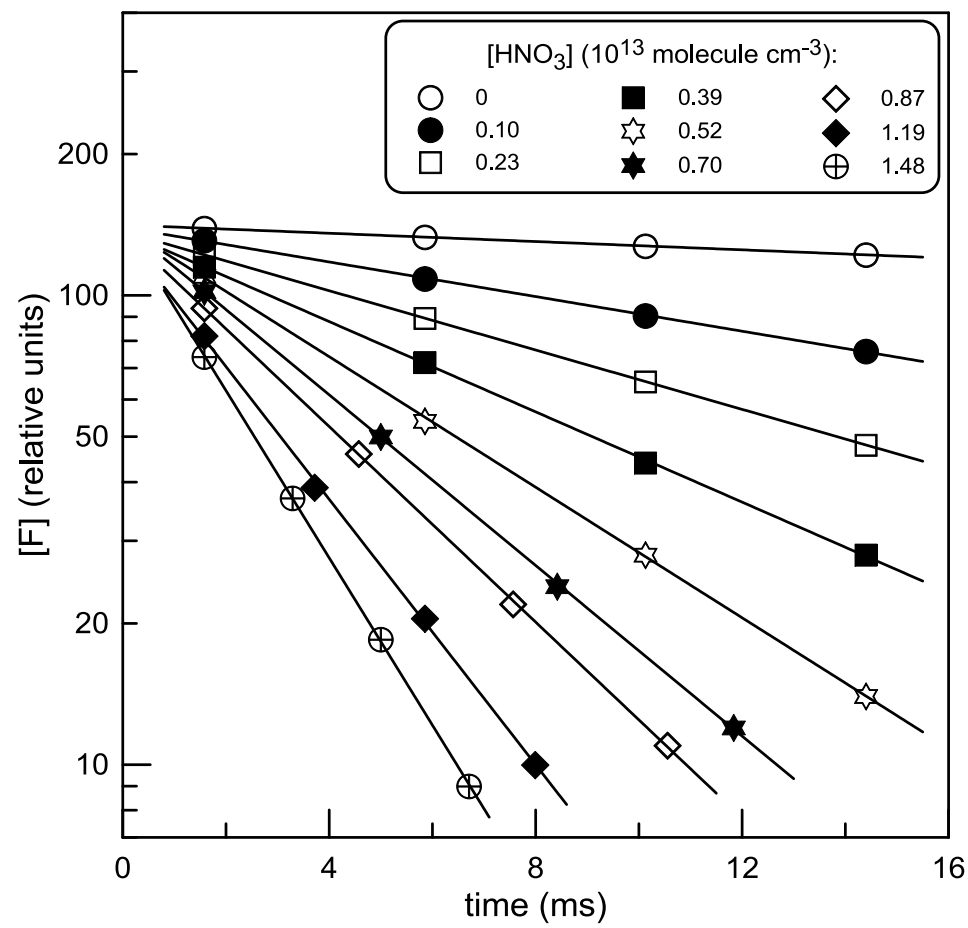

Figure 2 Examples of the pseudo-first-order decays of F-atom in reaction with $\mathrm{HNO}_{3}$ observed at $\mathrm{T}=253$ $\mathrm{K}$. Uncertainty on the measurements of the relative concentrations of F-atom $(\leq 5 \%)$ corresponds to the size of the symbols.

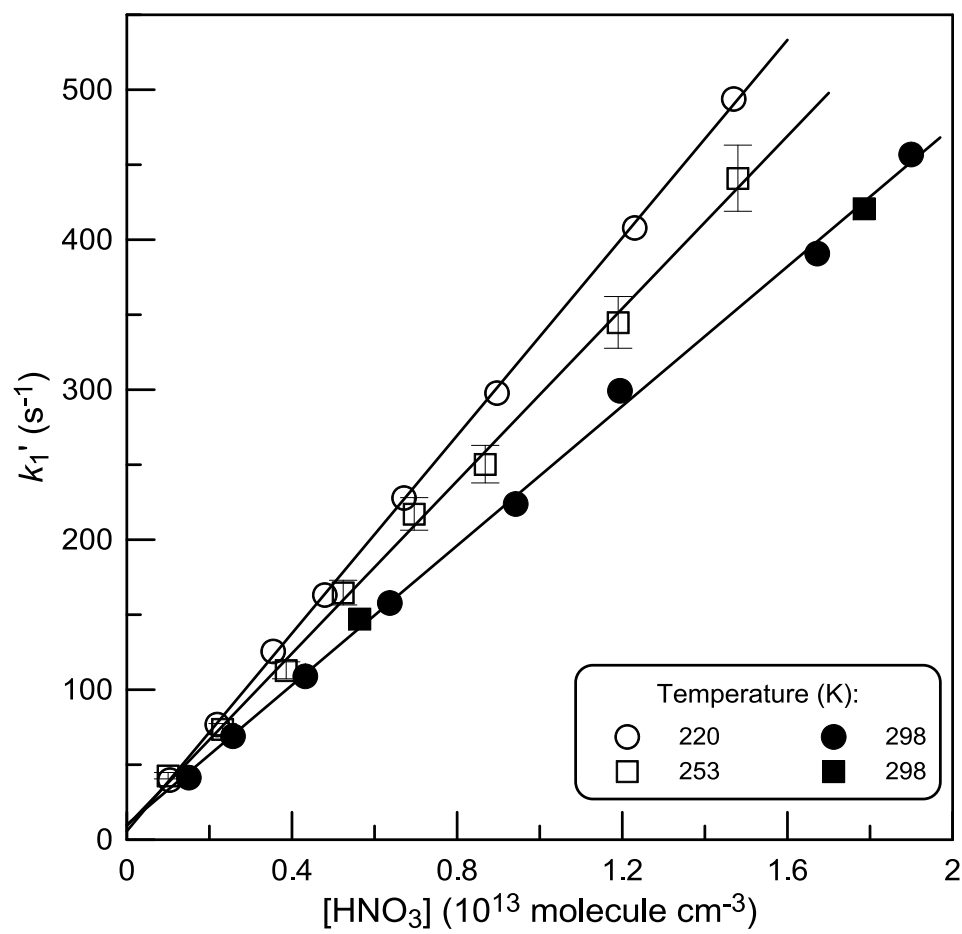


Figure 3 Pseudo-first-order rate constant $\left(k_{1}{ }^{\prime}\right)$ as a function of the concentration of $\mathrm{HNO}_{3}$ measured at different temperatures in the reactor covered with halocarbon wax: filled squares represent the data observed at $\mathrm{T}=298 \mathrm{~K}$ without addition of $\mathrm{NO}$ in the reactor (see text). Error bars represent typical uncertainties $(\leq 5 \%)$ on the determination of $k_{1}{ }^{\prime}$.

All measured values of $k_{1}{ }^{\prime}$ were corrected for axial and radial diffusion [10] of fluorine atoms. The diffusion coefficient of F-atom in He, $D_{0}=614 \times(\mathrm{T} / 298)^{1.75}$ Torr $\mathrm{cm}^{2} \mathrm{~s}^{-1}$ was estimated with Fuller's method [11]. Corrections were $\leq 10 \%$.

The possible impact of the secondary reaction

$$
\begin{aligned}
& \mathrm{F}+\mathrm{NO}_{3} \quad \rightarrow \quad \mathrm{FO}+\mathrm{NO}_{2} \\
& k_{3}=3 \times 10^{-11} \mathrm{~cm}^{3} \text { molecule } \mathrm{s}^{-1}(\mathrm{~T}=298 \mathrm{~K})[4]
\end{aligned}
$$

on the measurements of $k_{1}$ was insignificant due to relatively low initial concentrations of $\mathrm{F}$ atoms used. Even so, in the experiments on the measurements of $k_{1}$, NO $\left((1-3) \times 10^{13}\right.$ molecule $\mathrm{cm}^{-3}$ ) was added into reactive system in order to quantitatively suppress the possible secondary consumption of $\mathrm{F}$ atoms. In fact, NO inhibits the secondary chemistry through scavenging of $\mathrm{NO}_{3}$ radicals,

$$
\begin{aligned}
& \mathrm{NO}+\mathrm{NO}_{3} \quad \rightarrow \quad \mathrm{NO}_{2}+\mathrm{NO}_{2} \\
& k_{4}=1.5 \times 10^{-11} \exp (170 / \mathrm{T}) \mathrm{cm}^{3} \text { molecule }^{-1} \mathrm{~s}^{-1}(\mathrm{~T}=209-703 \mathrm{~K}) \text { [12], }
\end{aligned}
$$

and, on the other hand, does not contribute to $\mathrm{F}$ atom consumption under experimental conditions of the study,

$$
\mathrm{F}+\mathrm{NO}(+\mathrm{M}) \quad \rightarrow \quad \mathrm{FNO}(+\mathrm{M})
$$

$k_{5}$ being $<2 \times 10^{-14} \mathrm{~cm}^{3}$ molecule $\mathrm{s}^{-1}$ at $\mathrm{P}=2.7$ mbar and $\mathrm{T}=220-700 \mathrm{~K}$ [12].

The intercepts in the examples shown in Fig. 3 (as well as in all the experiments carried out at low temperatures in the reactor coated with halocarbon wax), $k_{\mathrm{w}}$, were in the range (3 10) $\mathrm{s}^{-1}$, in good agreement with the rate of F-atom decay measured in the absence of $\mathrm{HNO}_{3}$ in the reactor. However; in experiments with the uncoated quartz reactor at higher temperatures, the rate of F-atom consumption rapidly increased upon addition of even very low concentrations of $\mathrm{HNO}_{3}\left(<7 \times 10^{11}\right.$ molecule $\mathrm{cm}^{-3}$ in Fig. 4). As one can see in Fig. 4, the intercept of the linear fit to the experimental data $\left(\approx 70 \mathrm{~s}^{-1}\right)$ is much higher than the value of $k_{\mathrm{w}}\left(\approx 10 \mathrm{~s}^{-1}\right)$ measured in the absence of $\mathrm{HNO}_{3}$ in the reactor. The observed effect did not depend on the manner of $\mathrm{HNO}_{3}$ delivery to the reactor (from flask with a known $\mathrm{HNO}_{3} / \mathrm{He}$ mixture or flowing helium over a liquid $\mathrm{HNO}_{3}$ ) and did not seem to be related to the secondary chemistry, as shown in experiments with and without addition of NO in the reactor (Fig. 4). Becker et al. [5] reported a similar effect at $\mathrm{T}=298 \mathrm{~K}$ in experiments with uncoated quartz reactor and not in the reactor coated with halocarbon wax. The observation was 
attributed to the heterogeneous reaction between $\mathrm{F}$ atoms and $\mathrm{HNO}_{3}$, predominant at low concentrations of $\mathrm{HNO}_{3}[5]$.

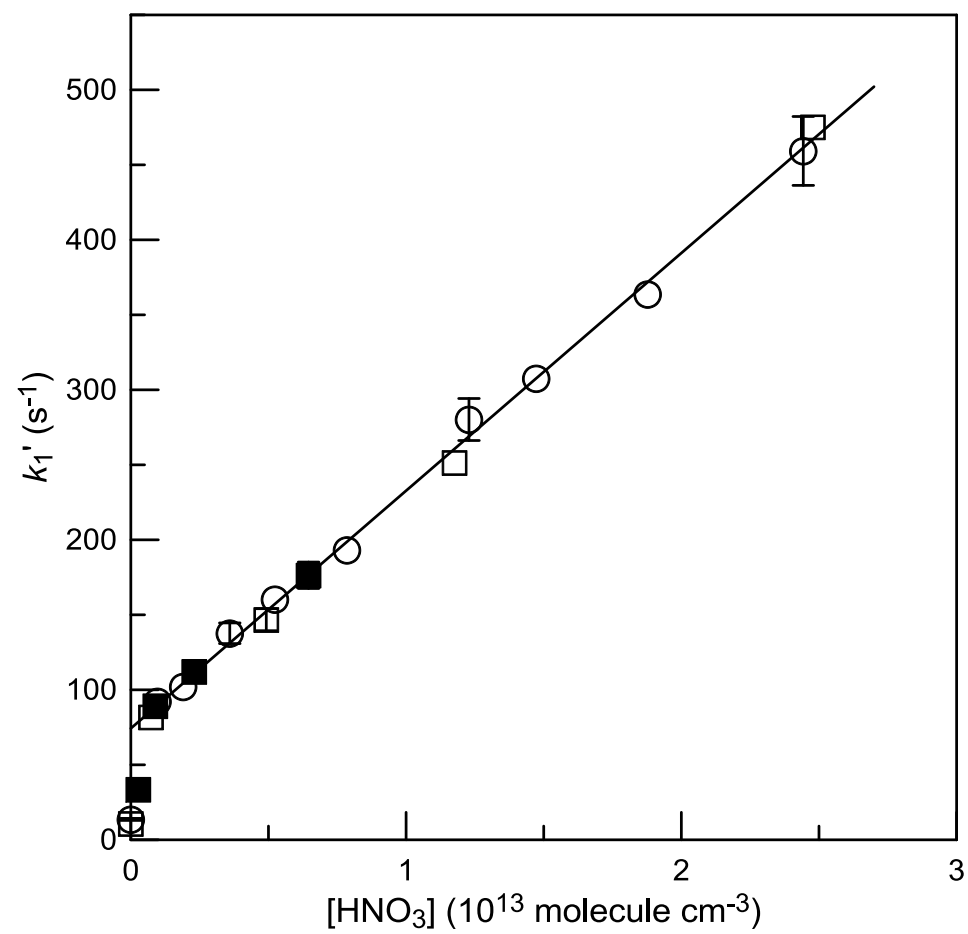

Figure 4 Pseudo-first-order rate constant $\left(k_{1}{ }^{\prime}\right)$ as a function of the concentration of $\mathrm{HNO}_{3}$ measured at $\mathrm{T}=$ $460 \mathrm{~K}$ in an uncoated quartz reactor: circles and squares represent the data observed with and without addition of $\mathrm{NO}$ in the reactor, respectively; filled and open symbols represent experiments with $\mathrm{HNO}_{3}$ introduced into the reactor from flask with a known $\mathrm{HNO}_{3} / \mathrm{He}$ mixture and flowing helium over a liquid $\mathrm{HNO}_{3}$, respectively.

Seeking to reduce the heterogeneous loss of $\mathrm{F}$-atoms in the presence of $\mathrm{HNO}_{3}$ in the reactor, we have coated the reactor with boric acid. However, this approach did not alleviate the observed effect: at all temperatures of the measurements the intercept $\left(40-100 \mathrm{~s}^{-1}\right)$ of the linear fit to the experimental values of $k_{1}{ }^{\prime}$ as a function of $\left[\mathrm{HNO}_{3}\right]$ was always much higher than F-atom loss observed in the absence of nitric acid in the reactor (10-20 $\left.\mathrm{s}^{-1}\right)$. This heterogeneous effect was not strongly correlated with temperature and could be reduced upon prolonged ( $\sim 1$ hour) exposure of the reactor to the reaction mixture. Examples of the data observed in boric acid coated reactor are shown in Fig. 5. Ultimately, the reaction rate constant was determined from the slope of the linear fit to the experimental data observed at relatively high concentrations of $\mathrm{HNO}_{3}$ (straight lines in Figs. 4 and 5), i.e. under assumption that heterogeneous contribution to the loss of F-atoms is independent of $\mathrm{HNO}_{3}$ concentration in the gas phase under these conditions and considering that the intercept is much lower than the measured maximum values of $k_{1}{ }^{\prime}$. All the results of the absolute measurements of $k_{1}$ are shown in Table I. The combined uncertainty on $k_{1}$ was estimated to be $\approx 15 \%$ by adding in 
quadrature statistical error $(\leq 5 \%)$ and those on the measurements of the flows $(5 \%)$, pressure $(3 \%)$, temperature $(1 \%)$ and absolute concentration of $\mathrm{HNO}_{3}(\leq 10 \%)$.

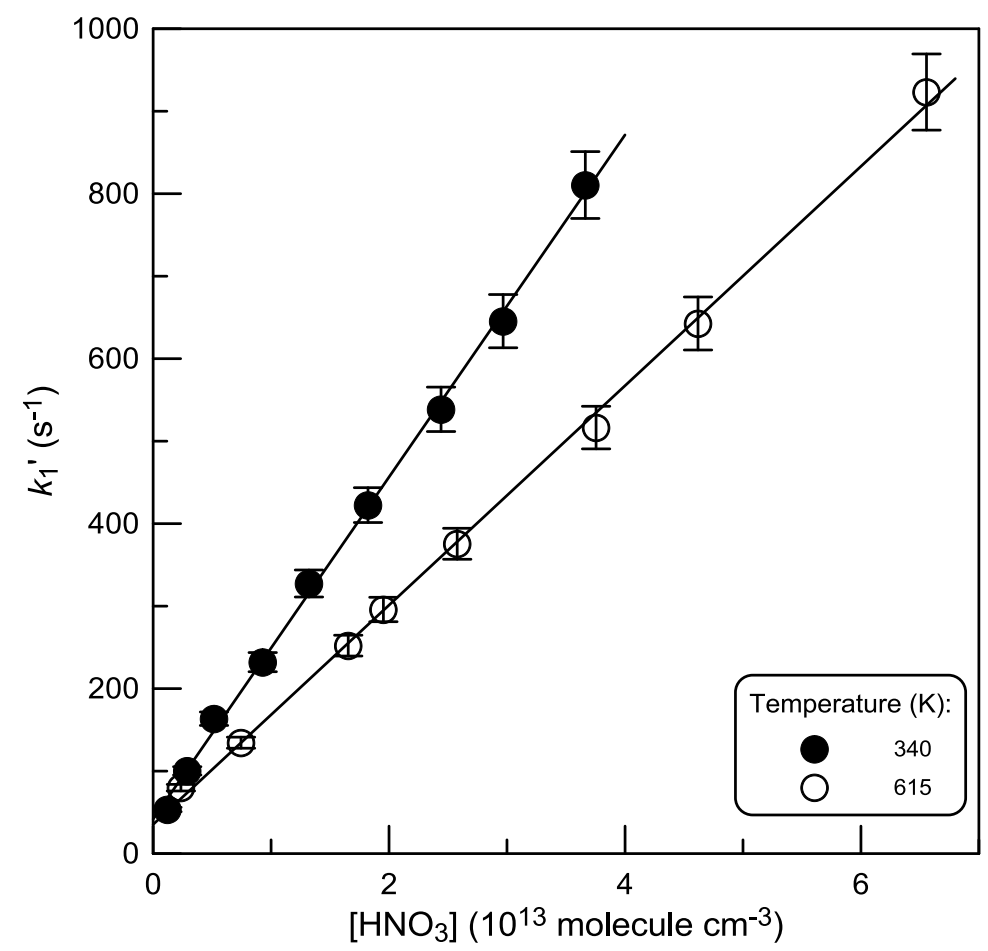

Figure 5 Pseudo-first-order rate constant $\left(k_{1}{ }^{\prime}\right)$ as a function of the concentration of $\mathrm{HNO}_{3}$ measured in the reactor coated with boric acid. Error bars represent typical uncertainties $(\leq 5 \%)$ on the determination of $k_{1}{ }^{\prime}$.

Relative rate measurements. Given the possible heterogeneous complications in the absolute measurements of the reaction rate constant at elevated temperatures (in quartz and boric acid coated reactors), we have carried out relative rate measurements with reaction of $\mathrm{F}$ atoms with $\mathrm{Br}_{2}$ as reference:

$$
\mathrm{F}+\mathrm{Br}_{2} \rightarrow \mathrm{FBr}+\mathrm{Br}
$$

In these experiments, fast titration of the initial concentration of $\mathrm{F}$ atoms, $[\mathrm{F}]_{0}$, by a mixture of excess $\mathrm{HNO}_{3}$ and $\mathrm{Br}_{2}$ was performed, and the yield of $\mathrm{FBr}$ was measured as a function of the $\left[\mathrm{HNO}_{3}\right] /\left[\mathrm{Br}_{2}\right]$ ratio. The concentration of $\mathrm{FBr}$ formed is defined by the fraction of $[\mathrm{F}]_{0}$ reacting with $\mathrm{Br}_{2}$ in reaction 2:

$$
[\mathrm{FBr}]=\frac{k_{2}\left[\mathrm{Br}_{2}\right]}{k_{2}\left[\mathrm{Br}_{2}\right]+k_{1}\left[\mathrm{HNO}_{3}\right]+k_{w}} \times[\mathrm{F}]_{0}
$$

Rearrangement of this expression leads to:

$$
\frac{[\mathrm{F}]_{0}}{[\mathrm{FBr}]}-1=\frac{k_{1}\left[\mathrm{HNO}_{3}\right]}{k_{2}\left[\mathrm{Br}_{2}\right]}+\frac{k_{w}}{k_{2}\left[\mathrm{Br}_{2}\right]}
$$

Experiments were carried out at constant concentration of $\mathrm{Br}_{2}$ (to keep the contribution of the second term in equation (I) constant) and $k_{1} / k_{2}$ could be obtained by plotting $\left([\mathrm{F}]_{0} /[\mathrm{FBr}]-1\right)$ 
as a function of the $\left[\mathrm{HNO}_{3}\right] /\left[\mathrm{Br}_{2}\right]$ ratio. This method did not need the measurements of the absolute concentrations $\mathrm{FBr}$ and $\mathrm{F}$-atoms because the initial concentration of F-atoms, $[\mathrm{F}]_{0}$, could be expressed as $\mathrm{FBr}$ signal in the absence of $\mathrm{HNO}_{3}$ in the reactor, when $\mathrm{F}$ is titrated with an excess of $\mathrm{Br}_{2}$. Thus, in the experiments, only the $\mathrm{FBr}$ signal was detected: first, in $\mathrm{HNO}_{3}$-free system, corresponding to $[\mathrm{F}]_{0}$, and then in the $\mathrm{Br}_{2}$ and $\mathrm{HNO}_{3}$-containing system, corresponding to the fraction of $[\mathrm{F}]_{0}$ reacted with $\mathrm{Br}_{2}$. Reaction time was around $0.01 \mathrm{~s}$, initial concentration of $\mathrm{F}$ atoms was varied in the range $(1.0-2.5) \times 10^{12}$ molecule $\mathrm{cm}^{-3}$, concentration of $\mathrm{Br}_{2}$ was (3-4) $) \times 10^{13}$ molecule $\mathrm{cm}^{-3}$, those of $\mathrm{HNO}_{3}$ are shown in Table I. All the measurements were conducted in the presence of $\mathrm{NO}$ in the reactor in order to remove $\mathrm{NO}_{3}$, product of the reaction (1), and to reduce (although insignificant under operating conditions) the impact of the secondary reaction $\mathrm{F}+\mathrm{NO}_{3}$. Examples of the observed experimental data are shown in Fig. 6. The variation of the initial concentration of F-atoms $(\mathrm{T}=339 \mathrm{~K})$ and that of NO $(\mathrm{T}=460 \mathrm{~K})$ had no impact on the results of the measurements. According to equation (I), the slopes of the linear dependences in Fig. 6 provide the values of $k_{1} / k_{2}$ at respective temperatures. Final values of $k_{1}$, calculated with independent of temperature $k_{2}=(1.28 \pm$ $0.20) \times 10^{-10} \mathrm{~cm}^{3}$ molecule $\mathrm{s}^{-1}(\mathrm{~T}=299-940 \mathrm{~K})$ [9] are presented in Table I.

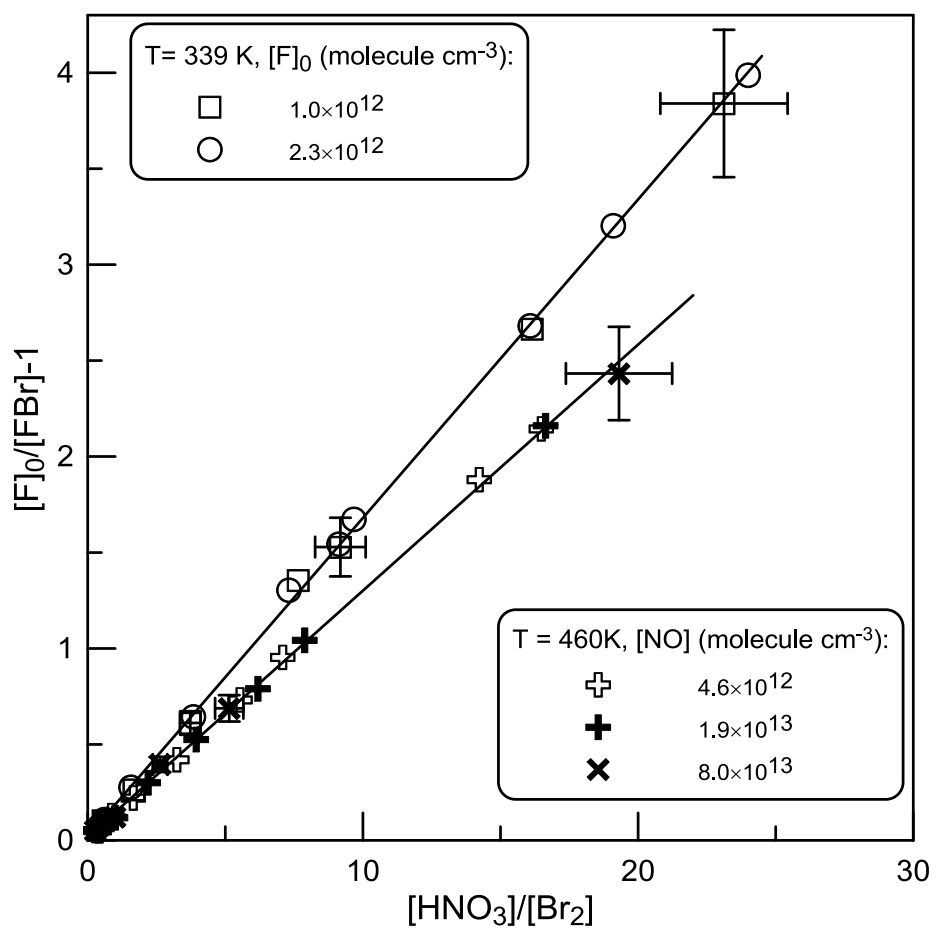

Figure $6 \mathrm{FBr}$ yield from $\mathrm{F}$-atom titration with $\mathrm{HNO}_{3}+\mathrm{Br}_{2}$ mixtures at $\mathrm{T}=339$ and $460 \mathrm{~K}$. The horizontal and vertical error bars represent estimated (of nearly $10 \%$ ) uncertainties on the respective values. 


\section{Reaction products}

Although the $\mathrm{NO}_{3}$-forming route of the reaction (1) is generally considered as the main one, two other exothermic channels are available for the reaction:

$$
\begin{aligned}
\mathrm{F}+\mathrm{HNO}_{3} & \rightarrow \mathrm{NO}_{3}+\mathrm{HF} & & \Delta_{\mathrm{r}} H^{\circ}=-143.7 \mathrm{~kJ} \mathrm{~mol}^{-1} \\
& \rightarrow \mathrm{OH}+\mathrm{FNO}_{2} & & \Delta_{\mathrm{r}} H^{\circ}=-22.5 \mathrm{~kJ} \mathrm{~mol}^{-1} \\
& \rightarrow \mathrm{HO}_{2}+\mathrm{FNO} & & \Delta_{\mathrm{r}} H^{\circ}=-20.4 \mathrm{~kJ} \mathrm{~mol}^{-1}
\end{aligned}
$$

The thermochemical data used for the calculations of $\Delta_{\mathrm{r}} H^{\circ}$ are from ref. [12]. In order to obtain experimental evidence of the dominance of the reaction channel (1a) both at low and high temperatures of the study, we have carried out additional experiments on the detection of the product of reaction (1), HF. Experiments consisted in a successive titration of the initial concentration of F-atom with an excess $\mathrm{H}_{2}$ and $\mathrm{HNO}_{3}$ accompanied with a direct detection of the reaction product, HF. This allowed to measure the yield of HF in the reaction of F-atom with $\mathrm{HNO}_{3}$ relatively to that in the reaction of $\mathrm{F}$ with $\mathrm{H}_{2}$, where the yield of $\mathrm{HF}$ is $100 \%$. The advantage of this approach is that it does not require the measurements of the absolute concentrations of either F-atoms or HF. Experiments have been carried out at two temperatures: 235 and $615 \mathrm{~K}$. Reaction time was nearly $0.02 \mathrm{~ms},\left[\mathrm{HNO}_{3}\right] \approx 3 \times 10^{13}$ and $10^{14}$, $\left[\mathrm{H}_{2}\right] \approx 6 \times 10^{13}$ and $2 \times 10^{13},[\mathrm{~F}]_{0}=(0.25-3.6) \times 10^{12}$ and $(0.15-3.1) \times 10^{12}$ molecule $\mathrm{cm}^{-3}$ at $\mathrm{T}=$ 235 and $615 \mathrm{~K}$, respectively. The observed data are shown in Fig. 7.

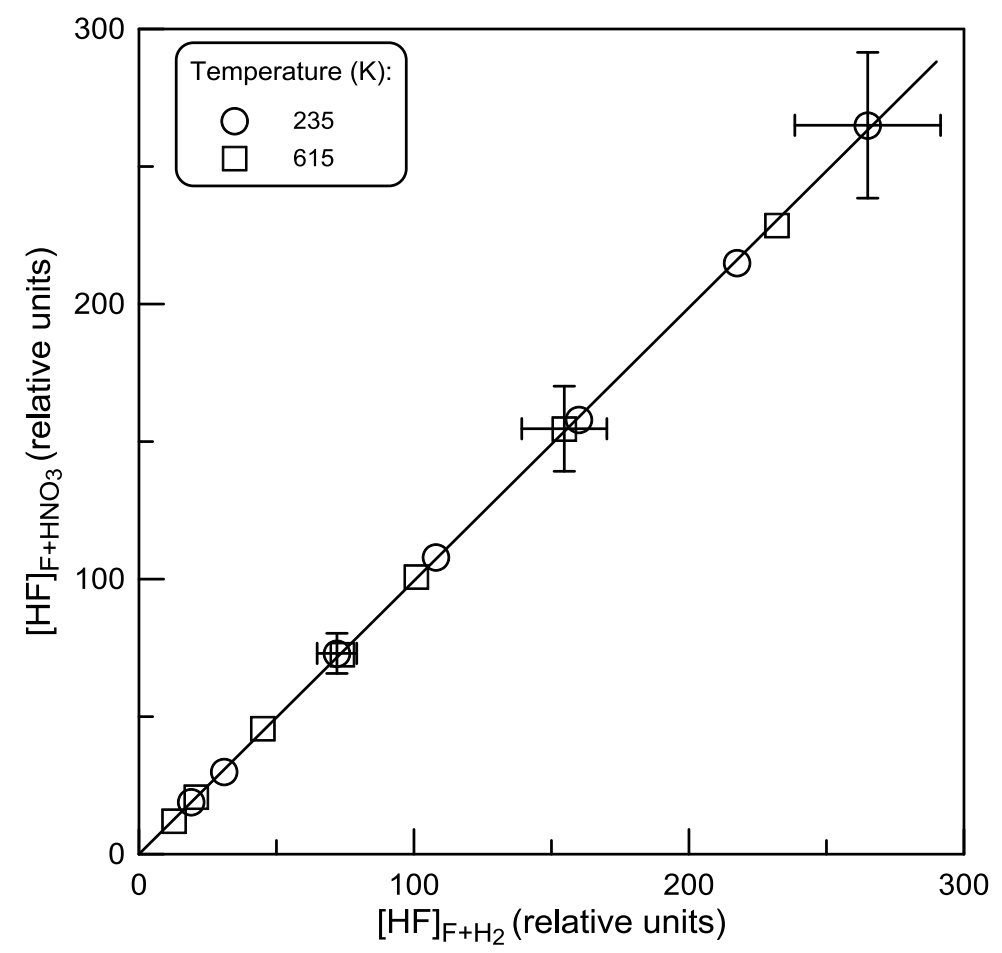


Figure 7 Concentration of $\mathrm{HF}$ formed in reaction of F-atom with $\mathrm{HNO}_{3}$ as a function of the concentration of $\mathrm{HF}$ formed in F-atom reaction with $\mathrm{H}_{2}$ upon consumption of the same concentration of F-atoms. Error bars correspond to the upper limit (of 10\%) of the uncertainty on the determination of the relative concentrations.

The linear through origin fit to all the data observed at two temperatures (straight line in Fig. 7) provides independent of temperature branching ratio for the HF forming channel of reaction (1): $0.993 \pm 0.005(2 \sigma)$, indicating that that $\mathrm{NO}_{3}+\mathrm{HF}$ pathway of the reaction (1) is the dominant one in the temperature range of the present study.

\section{Comparison with previous data}

Figure 8 summarizes the results of previous and current measurements of the rate constant of reaction (1). Mellouki et al. [3] have measured the reaction rate constant at $\mathrm{T}=298 \mathrm{~K}$ in a fast-flow reactor combined with electron spin resonance (ESR) spectroscopy: $k_{1}=(2.7 \pm$ $0.5) \times 10^{-11} \mathrm{~cm}^{3}$ molecule $\mathrm{s}^{-1}$. Rahman et al. [4], using flow reactor combined with mass spectrometry as a detection method have reported $k_{1}=(2.1 \pm 1.0) \times 10^{-11} \mathrm{~cm}^{3}$ molecule $\mathrm{s}^{-1}$ at T $=298 \mathrm{~K}$ which was derived from kinetics of the products of reaction (1), $\mathrm{HF}$ and $\mathrm{NO}_{3}$, and from the kinetics of $\mathrm{HNO}_{3}$ consumption in excess of $\mathrm{F}$ atoms. Afterwards the rate constant has been re-determined in the same group, $k_{1}=(2.2 \pm 0.2) \times 10^{-11} \mathrm{~cm}^{3}$ molecule $\mathrm{s}^{-1}$ at $\mathrm{T}=298$ $\mathrm{K}$, employing fast flow system and following $\mathrm{NO}_{3}$ formation and F-atom decays by mass spectrometry and ESR method, respectively [5]. Results of these room temperature measurements of $k_{1}$ are in agreement with the present data in the range of the reported experimental uncertainties. In the only temperature dependent study of reaction (1), Wine et al. [2] used a time-resolved long-path laser absorption technique to monitor the kinetics of reaction product, $\mathrm{NO}_{3}$ radical, upon pulsed laser photolysis of $\mathrm{F}_{2} / \mathrm{HNO}_{3} / \mathrm{He}$ mixture in the temperature range $260-373 \mathrm{~K}$. The authors represented $k_{1}$ by the Arrhenius expression $k_{1}=$ $(6.0 \pm 2.6) \times 10^{-12} \exp ((400 \pm 120) / \mathrm{T})$ between 260 and $320 \mathrm{~K}$ and with independent of temperature value of $k_{1}=(2.0 \pm 0.3) \times 10^{-11} \mathrm{~cm}^{3}$ molecule $\mathrm{s}^{-1}$ in the temperature range $335-373$

K. As one can see in Fig. 8, the present measurements do not confirm the independence of $k_{1}$ of temperature at $\mathrm{T}>335 \mathrm{~K}$, showing negative temperature dependence of $k_{1}$ in the whole temperature range of this study, 220-700 K. At the same time, the absolute values of $k_{1}$ measured by Wine et al. [2] are in excellent agreement with the present data which can be represented by the following Arrhenius expression:

$$
k_{1}=(8.2 \pm 0.4) \times 10^{-12} \exp ((315 \pm 15) / \mathrm{T}) \mathrm{cm}^{3} \text { molecule }^{-1} \mathrm{~s}^{-1}
$$

between 220 and $700 \mathrm{~K}$ and with $2 \sigma$ uncertainties representing the precision of the fit. 
The observed negative temperature dependence of the reaction rate constant may be considered as an indication of a complex reaction mechanism that includes formation of an intermediate energized $\mathrm{F} \bullet \mathrm{HNO}_{3}$ adduct followed either by its dissociation back to reactants or to reaction products. Similar mechanism was proposed for analogous reaction $\mathrm{OH}+\mathrm{HNO}_{3} \rightarrow$ $\mathrm{NO}_{3}+\mathrm{H}_{2} \mathrm{O}$ (e.g. [13]). The rate constant of the reaction $\mathrm{OH}+\mathrm{HNO}_{3}$ was found to be pressure dependent below room temperature (e.g. [14]). In this context, we have checked for the possible pressure dependence of the rate constant of the reaction $\mathrm{F}+\mathrm{HNO}_{3}$ in the lower temperature range covered in the present study. The values of $k_{1}$ at $\mathrm{T}=233,235$ and $237 \mathrm{~K}$ presented in Table I and Fig. 8 were measured at total pressure of 0.67, 2.7 and 6.7 mbar, respectively. As one can note, $k_{1}$ was found to be pressure independent in the range of the experimental uncertainty (at least, at low temperatures of the present study), although this does not exclude a possible pressure dependence of $k_{1}$ at higher pressures.

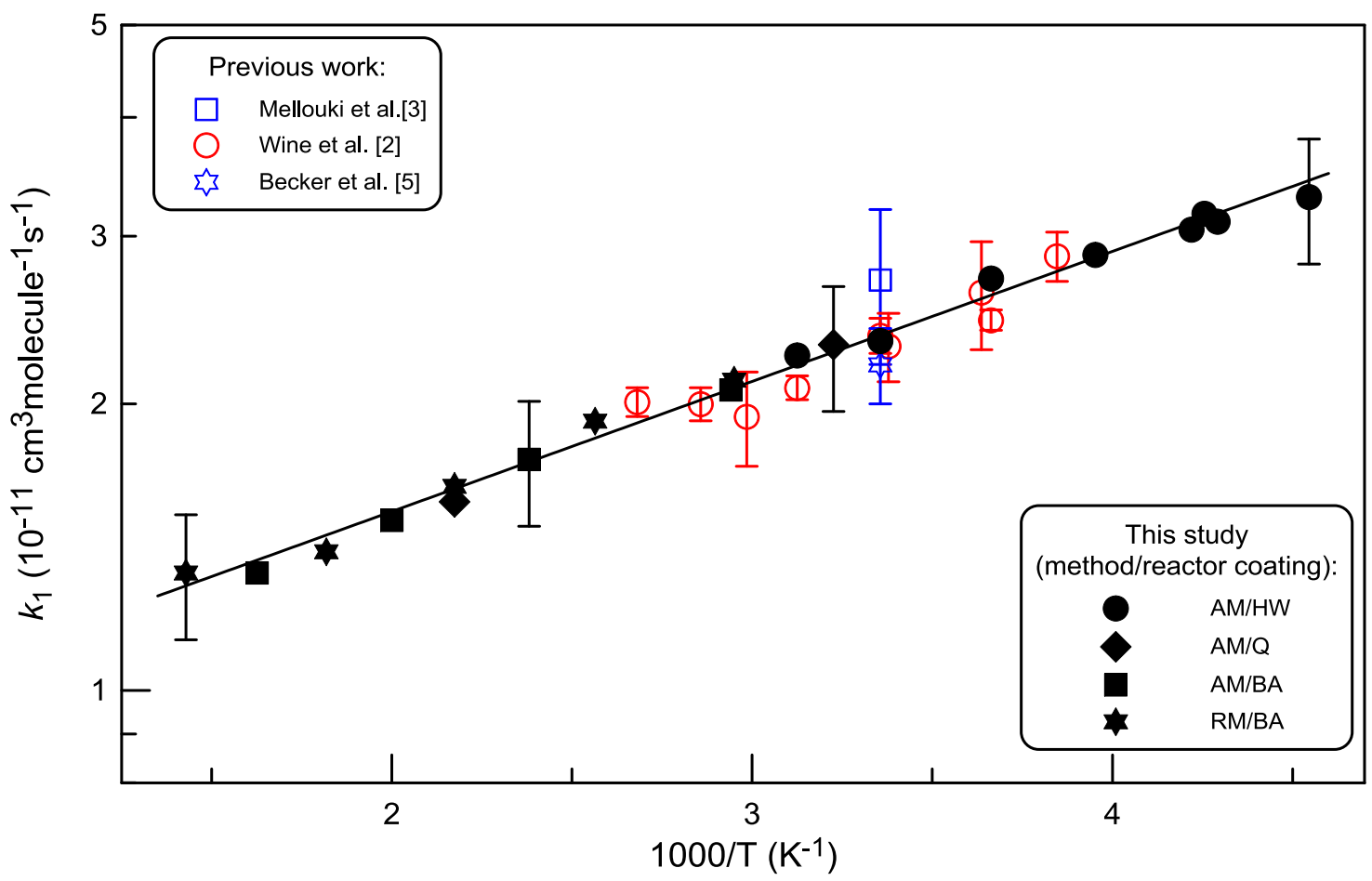

Figure 8 Summary of the measurements of the rate constant of reaction (1). AM: absolute measurements; RM: relative measurements; HW: halocarbon wax; Q: quartz; BA: boric acid. Partially shown error bars on the present data correspond to estimated $15 \%$ uncertainty on the measurements of $k_{1}$. Uncertainties on $k_{1}$ reported in previous studies correspond to $2 \sigma[2,5]$ and total estimated uncertainty [3].

\section{CONCLUSION}

In this work, using a discharge-flow reactor combined with mass spectrometry, we have measured the rate constant of the reaction of fluorine atoms with nitric acid as a function of temperature in an extended temperature range, 220-700 $\mathrm{K}$. The 
temperature dependence of the rate constant of this reaction, very often used as a source of $\mathrm{NO}_{3}$ radical (important intermediate in nighttime atmospheric chemistry) in laboratory, was found to be in good agreement with the only other temperature dependent study at $\mathrm{T}=260-373 \mathrm{~K}$ and was extended to lower $(220 \mathrm{~K})$ and higher $(700 \mathrm{~K})$ temperatures. Experiments on detection of the reaction product, HF, have shown that the $\mathrm{NO}_{3}$ and $\mathrm{HF}$ forming channel of the title reaction is dominant, if not quantitative one in the whole temperature range of the study. The negative temperature dependence of the rate constant seems to indicate a complex reaction mechanism, probably, involving formation of long lived intermediate complex followed by its rearrangement and dissociation to products.

Financial support from CNRS is gratefully acknowledged. 


\section{BIBLIOGRAPHY}

1. Wayne, R. P.; Barnes, I.; Biggs, P.; Burrows, J. P.; Canosa-Mas, C. E.; Hjorth, J.; Le Bras, G.; Moortgat, G. K.; Perner, D.; Poulet, G.; Restelli, G.; Sidebottom, H. The nitrate radical: Physics, chemistry, and the atmosphere. Atmos. Environ. 1991, 25A, 1203.

2. Wine, P. H.; Wells, J. R.; Nicovich, J. M. Kinetics of the reactions of atomic fluorine $\left({ }^{2} \mathrm{P}\right)$ and atomic chlorine $\left({ }^{2} \mathrm{P}\right)$ with nitric acid. J. Phys. Chem. 1988, 92, 2223 2228.

3. Mellouki, A.; Le Bras, G.; Poulet, G. Discharge flow kinetic study of nitrate radical reactions with free radicals: the reaction of nitrate radical with chlorine atom. J. Phys. Chem. 1987, 91, 5760-5764.

4. Rahman, M. M.; Becker, E.; Benter, T.; Schindler, R. N. A Gasphase Kinetic Investigation of the System $\mathrm{F}+\mathrm{HNO}_{3}$ and the Determination of Absolute Rate Constants for the Reaction of the $\mathrm{NO}_{3}$ Radical with $\mathrm{CH}_{3} \mathrm{SH}$, 2-Methylpropene, 1,3-Butadiene and 2,3-Dimethyl-2-Butene. Ber. Bunsenges. Phys. Chem. 1988, 92, 91-100.

5. Becker, E.; Benter, T.; Kampf, R.; Schindler, R. N.; Wille, U. A Redetermination of the Rate Constant of the Reaction $\mathrm{F}+\mathrm{HNO}_{3} \rightarrow \mathrm{HF}+\mathrm{NO}_{3}$. Ber. Bunsenges. Phys. Chem. 1991, 95, 1168-1173.

6. Bedjanian, Y. Reaction $\mathrm{F}+\mathrm{C}_{2} \mathrm{H}_{4}$ : Rate Constant and Yields of the Reaction Products as a Function of Temperature over 298-950 K. J. Phys. Chem. A 2018, 122, 31563162 .

7. Bedjanian, Y.; Lelièvre, S.; Le Bras, G. Kinetic and mechanistic study of the F atom reaction with nitrous acid. J. Photochem. Photobio. A 2004, 168, 103-108.

8. Morin, J.; Romanias, M. N.; Bedjanian, Y. Experimental Study of the Reactions of $\mathrm{OH}$ Radicals with Propane, n-Pentane, and n-Heptane over a Wide Temperature Range. Int. J. Chem. Kinet. 2015, 47, 629-637.

9. Bedjanian, Y. Kinetics and Products of the Reactions of Fluorine Atoms with CINO and $\mathrm{Br}_{2}$ from 295 to 950 K. J. Phys. Chem. A 2017, 121, 8341-8347.

10. Kaufman, F. Kinetics of Elementary Radical Reactions in the Gas Phase. J. Phys. Chem. 1984, 88, 4909-4917. 
11. Tang, M. J.; Cox, R. A.; Kalberer, M. Compilation and evaluation of gas phase diffusion coefficients of reactive trace gases in the atmosphere: volume 1. Inorganic compounds. Atmos. Chem. Phys. 2014, 14, 9233-9247.

12. Burkholder, J. B.; Sander, S. P.; Abbatt, J.; Barker, J. R.; Huie, R. E.; Kolb, C. E.; Kurylo, M. J.; Orkin, V. L.; Wilmouth, D. M.; Wine, P. H. Chemical Kinetics and Photochemical Data for Use in Atmospheric Studies, Evaluation No. 18, JPL Publication 15-10, Jet Propulsion Laboratory, Pasadena, 2015 http://jpldataeval.jpl.nasa.gov, accessed March 2019.

13. Brown, S. S.; Burkholder, J. B.; Talukdar, R. K.; Ravishankara, A. R. Reaction of hydroxyl radical with nitric acid: insignts into its mechanism. J. Phys. Chem. A 2001, 105, 1605-1614.

14. Brown, S. S.; Talukdar, R. K.; Ravishankara, A. R. Reconsideration of the Rate Constant for the Reaction of Hydroxyl Radicals with Nitric Acid. J. Phys. Chem. A 1999, 103, 3031-3037. 


\section{TABLES}

Table I Reaction $\mathrm{F}+\mathrm{HNO}_{3}$ : Summary of the Measurements of the Rate Constant

\begin{tabular}{lccccc}
\hline$T(\mathrm{~K})$ & $\begin{array}{c}\text { number of } \\
\text { kinetic runs }\end{array}$ & $\begin{array}{c}{\left[\mathrm{HNO}_{3}\right]} \\
\left(10^{13} \text { molecule } \mathrm{cm}^{-3}\right)\end{array}$ & $\begin{array}{c}k_{1}{ }^{2} \\
\left(10^{-11} \mathrm{~cm}^{3} \text { molecule } \mathrm{s}^{-1}\right)\end{array}$ & $\begin{array}{c}\text { reactor } \\
\text { surface }\end{array}$ & method $^{c}$ \\
\hline 220 & 8 & $0.10-1.47$ & 3.30 & $\mathrm{HW}$ & $\mathrm{AM}$ \\
233 & 7 & $0.13-0.99$ & 3.11 & $\mathrm{HW}$ & $\mathrm{AM}$ \\
235 & 8 & $0.10-1.49$ & 3.17 & $\mathrm{HW}$ & $\mathrm{AM}$ \\
237 & 8 & $0.06-0.67$ & 3.05 & $\mathrm{HW}$ & $\mathrm{AM}$ \\
253 & 8 & $0.10-1.50$ & 2.87 & $\mathrm{HW}$ & $\mathrm{AM}$ \\
273 & 8 & $0.10-1.50$ & 2.71 & $\mathrm{HW}$ & $\mathrm{AM}$ \\
298 & 10 & $0.15-1.91$ & 2.33 & $\mathrm{HW}$ & $\mathrm{AM}$ \\
310 & 8 & $0.07-1.41$ & 2.31 & $\mathrm{Q}$ & $\mathrm{AM}$ \\
320 & 8 & $0.18-1.63$ & 2.25 & $\mathrm{HW}$ & $\mathrm{AM}$ \\
339 & 10 & $1.17-66.7$ & 2.12 & $\mathrm{BA}$ & $\mathrm{RM}$ \\
340 & 9 & $0.12-3.70$ & 2.07 & $\mathrm{BA}$ & $\mathrm{AM}$ \\
390 & 10 & $1.65-61.8$ & 1.92 & $\mathrm{BA}$ & $\mathrm{RM}$ \\
420 & 14 & $0.32-4.20$ & 1.75 & $\mathrm{BA}$ & $\mathrm{AM}$ \\
460 & 24 & $1.02-76.5$ & 1.64 & $\mathrm{BA}$ & $\mathrm{RM}$ \\
460 & 16 & $0.09-2.47$ & 1.58 & $\mathrm{Q}$ & $\mathrm{AM}$ \\
500 & 9 & $0.12-5.12$ & 1.51 & $\mathrm{BA}$ & $\mathrm{AM}$ \\
550 & 8 & $1.20-59.2$ & 1.40 & $\mathrm{BA}$ & $\mathrm{RM}$ \\
615 & 8 & $0.24-6.6$ & 1.33 & $\mathrm{BA}$ & $\mathrm{AM}$ \\
700 & 10 & $1.12-37.7$ & 1.33 & $\mathrm{RM}$ \\
\hline
\end{tabular}

${ }^{a}$ Estimated uncertainty on $k_{1}$ is 15 and $20 \%$ for absolute and relative rate measurements, respectively.

${ }^{b}$ HW: halocarbon wax; Q: quartz; BA: boric acid.

${ }^{c}$ AM: absolute measurements; RM: relative rate measurements. 


\section{FIGURE LEGENDS}

Figure 1 Diagram of the flow reactor.

Figure 2 Examples of the pseudo-first-order decays of F-atom in reaction with $\mathrm{HNO}_{3}$ observed at $\mathrm{T}=253 \mathrm{~K}$. Uncertainty on the measurements of the relative concentrations of $\mathrm{F}$-atom $(\leq 5 \%)$ corresponds to the size of the symbols.

Figure 3 Pseudo-first-order rate constant $\left(k_{1}{ }^{\prime}\right)$ as a function of the concentration of $\mathrm{HNO}_{3}$ measured at different temperatures in the reactor covered with halocarbon wax: filled squares represent the data observed at $\mathrm{T}=298 \mathrm{~K}$ without addition of NO in the reactor (see text). Error bars represent typical uncertainties $(\leq 5 \%)$ on the determination of $k_{1}{ }^{\prime}$.

Figure 4 Pseudo-first-order rate constant $\left(k_{1}{ }^{\prime}\right)$ as a function of the concentration of $\mathrm{HNO}_{3}$ measured at $\mathrm{T}=460 \mathrm{~K}$ in an uncoated quartz reactor: circles and squares represent the data observed with and without addition of NO in the reactor, respectively; filled and open symbols represent experiments with $\mathrm{HNO}_{3}$ introduced into the reactor from flask with a known $\mathrm{HNO}_{3} / \mathrm{He}$ mixture and flowing helium over a liquid $\mathrm{HNO}_{3}$, respectively.

Figure 5 Pseudo-first-order rate constant $\left(k_{1}{ }^{\prime}\right)$ as a function of the concentration of $\mathrm{HNO}_{3}$ measured in the reactor coated with boric acid. Error bars represent typical uncertainties $(\leq 5 \%)$ on the determination of $k_{1}{ }^{\prime}$.

Figure $6 \mathrm{FBr}$ yield from $\mathrm{F}$-atom titration with $\mathrm{HNO}_{3}+\mathrm{Br}_{2}$ mixtures at $\mathrm{T}=339$ and $460 \mathrm{~K}$. The horizontal and vertical error bars represent estimated (of nearly $10 \%$ ) uncertainties on the respective values.

Figure 7 Concentration of $\mathrm{HF}$ formed in reaction of F-atom with $\mathrm{HNO}_{3}$ as a function of the concentration of $\mathrm{HF}$ formed in F-atom reaction with $\mathrm{H}_{2}$ upon consumption of the same concentration of F-atoms. Error bars correspond to the upper limit (of 10\%) of the uncertainty on the determination of the relative concentrations.

Figure 8 Summary of the measurements of the rate constant of reaction (1). AM: absolute measurements; RM: relative measurements; HW: halocarbon wax; Q: quartz; BA: boric acid. Partially shown error bars on the present data correspond to estimated $15 \%$ uncertainty on the measurements of $k_{1}$. Uncertainties on $k_{1}$ reported in previous studies correspond to $2 \sigma[2,5]$ and total estimated uncertainty [3]. 